\title{
The Influence of Combined Oral Contraceptive on Erythrocyte Sedimentation Rate, Total Protein, Albumin, Globulin and Fibrinogen in Women
}

\author{
*Sunday O. Ita, Confidence W. Ihua, Uyai E. Francis, Emem B. Ukpong \\ *Department of Physiology, Faculty of Basic Medical Sciences, College of Health Sciences, \\ University of Uyo, Uyo. Akwalbom State.
}

\begin{abstract}
:
Background: Uses of hormonal contraceptives by women have been shown to be associated with alteration in several blood and cardiovascular properties. In the light of this, the present study was designed to investigate effects of two different combinations of oral contraceptives on erythrocyte sedimentation rate, total protein, albumin, globulin and fibrinogen in women.

Materials and Methods: The study involved 50 volunteer female undergraduate students of University of Port Harcourt (20-30 years of age), who were not on contraceptives served as control (group I). Group II consisted of 30 women who were on combined oral contraceptives (methyloestranolone 5mg and methyloestradiol $0.3 \mathrm{mg}$ ), and group III consisted of 40 women who were on norgesterol-estradiol (1mg and $50 \mu \mathrm{g}$ respectively). These were apparently healthy women attending the Family Planning Units of the University of Port Harcourt Teaching Hospital who were age-matched with the control group.
\end{abstract}

Results: The results showed that while high estrogen combined contraceptives (group II) significantly increased ESR, globulin and fibrinogen; it significantly reduced total protein and albumin compared with the control group ( $p<0.05)$. Group III (low estrogen combined contraceptives) did not alter ESR, total protein, albumin, globulin and fibrinogen significantly when compared with the control group. Comparison between groups II and III showed that low estrogen content combined contraceptives (group III) significantly reduced erythrocyte sedimentation rate, globulin and fibrinogen, while it significantly increased total protein and albumin.

Conclusion: It is therefore concluded that high estrogen content combined oral contraceptive by markedly altering serum total protein, albumin, globulin and fibrinogen distribution to increase erythrocyte sedimentation rate in apparently healthy women has the potential of increasing risk for associated inflammatory cardiovascular disorders in users if taken without caution. This is more important as chronic use of oral contraceptives containing estrogen may increase risk of raising blood pressure and the development of hypertension in users.

Keywords: Combinedoral contraceptives, erythrocyte sedimentation rate, total protein, albumin, globulin, fibrinogen, women.

\section{INTRODUCTION}

Contraception involved deliberate practices by couples to prevent sexual intercourse resulting in the birth of a child, or more strictly speaking, to preclude conception [1]. Contraceptive methods include barrier and chemical methods locally applied to the genitals; intrauterine, surgical, and the more recent use of hormonal contraceptives.

Hormonal contraception refers to birth control methods that act on the endocrine system. Almost all methods are composed of steroid hormones. Hormonal contraceptives while inhibiting ovulation and fertilization are associated with some side effects in the body of users. Combined hormonal contraceptives are said to be associated with a slight increases in cardiovascular risk, including an increased risk of venous and arterial thrombosis, blood clots that can cause permanent disability or even death. While oral contraceptives reduce the risk of ovarian cancer and endometrial cancer, these drugs increase the risk of breast and cervical cancer [2,3]. Some can reduce water retention, and 


\section{Sunday O. Ita et al.}

several are used to treat mild to moderate acne. Some types of combinations of hormonal contraceptives may reduce the symptoms of premenstrual dysphoric disorders and can also reduce heavy menstrual bleeding and painful menstruation. The benefits of hormonal contraceptive use are greater than the risk of pregnancy, because pregnancy can also increase those risks [2, 4].

The erythrocyte sedimentation rate (ESR) is a common haematological test and a non-specific measure of inflammation [5]. ESR is governed by the balance between pro-sedimentation factors, mainly fribrinogen, and those factors resisting blood sedimentation, namely the negative charge of the erythrocytes. One important characteristic of the red blood cells that play prominent role in ESR is the ability to form rouleaux. Presence of high molecular weight proteins facilitates rouleauxformation, this in turn increase ESR. One of such high molecular weight proteins is fibrinogen which is involved in clotting, platelets activation and elevation of blood viscosity [6].

The ESR is increased by any cause or focus of inflammation and it is also increased in pregnancy, inflammation, anaemia or rheumatoid arthritis, and decreased in polycythaemia, sickle-cell anaemia, hereditary spherocytosis, and congestive heart failure. The basal ESR can sometimes be useful in diagnosing some diseases such as multiple myeloma, temporal arthritis, polymyalgiarheumatica, various auto-immune diseases, systemic lupus erythematosus, rheumatoid arthritis and chronic kidney disease [7].

Since the introduction of the contraceptives into the market at the middle of the 20th century, several millions of women in the reproductive age group all over the world have made use of it to prevent unwanted pregnancy and abortions and also to permit improvement in the timing of child's birth [8]. The efficacy of the contraceptives has never been in doubt, and more worrisome are the documented side effects. Evidence suggesting negative effects of contraceptive on health emerged shortly after their introduction. In addition, the wide spread use of hormonal contraceptives provides an opportunity for assessing the influence of estrogens and progestrogens on various biochemical parameters of the female [9].

The biochemical profile of women on contraceptives showed different changes in plasma total protein, albumin globulin and cholesterol levels. During contraceptive medication the most pronounced changes are usually increase in the concentration of total proteins and a decrease in albumin concentration [10]. Also electrophoretic determination had shown a decrease of albumin and increases in globulins during the administration of contraceptives [8]. It has been suggested that the increased total protein levels in certain subjects on oral contraceptives might be due to an increase in certain carrier proteins such as transferrin, ceruloplasmin, hormone binding globulin, and thyroxin binding prealbumin[7]. Also, the estrogen content in contraceptives is said to be responsible for the increased total proteins [11]. Furthermore, quantitative determinations of serum proteins by other researchers have also demonstrated an increase in lipoproteins, cerulloplasmins, alpha 1-antitrypsin and transferrin after the administration of estrogens or oral contraceptives [12].

In pregnancy ESR is reportedly raised above the usual accepted limits of normal, and since the physiological effect of contraceptives are in many ways are similar to those of pregnancy, it is therefore, very vital to ascertain the changes on other biochemical parameters in the body of users. Paucity of information on erythrocytes sedimentation rate (ESR) in women taking oral contraceptives necessitated this investigation. This study was designed with the primary objective of assessing the influence of two different types of combined oral contraceptives on ESR total protein, albumin and globulin.

\section{MATERIALS AND METHODS}

\section{Subject Selection}

Blood sample collection for this research work were done in the Family Planning Units of University of Port Harcourt Teaching Hospital (UPTH) and the volunteer female undergraduates students of University of Port Harcourt who were not on contraceptive constituted the control subject, after approval from Ethics Committee of the same hospital.

Blood samples were collected from female subjects using questionnaires as template or guide. Efforts were made to ensure that the subjects conform to the following inclusion criteria based on questionnaires issued before mobilizing them for study.

A total of 120 women subjects were involved in this study and divided into three groups. These were group I that consisted of 50 female volunteer subjects without contraceptives which served as control 
group, group II, which consisted of 30 women on combined methyloestranolone and methyloestradiol (5mg and $0.3 \mathrm{mg}$ respectively), and group III, which consisted of 40 women on combined norgesterolestradiol ( $1 \mathrm{mg}$ and $5 \mu \mathrm{g}$ respectively).

\section{Blood Sample Collection}

Blood samples were collected by a vacutainer in the morning hours into plains sample bottles and stored for biochemical analysis.

The blood samples in the plain sample bottles were spun with table top centrifuge (RM-12 Micro centrifuges, REMI, England) at 3000rpm for 10 minutes. Then the serum was separated gently with the help of micropipette and stored in labeled eppendrof tubes at $-20^{\circ} \mathrm{C}$ until assayed for serum chemistry.

\section{Estimation of Total Serum Proteins}

In estimating the total protein, biuret method was used with total protein reagents (Randox, USA) according to method described by Henry et al., [13].

\section{Evaluation of Albumin}

The albumin estimation was done using albumin reagent (Dialab, France) [14].

\section{Determination of Serum Globulin}

The determination of serum globulin concentration was carried out using the method described by Tietz[14] by subtracting the concentration of serum albumin from the total protein content determined using Biuret method as described by Henry et al., [13].

\section{Determination of Fibrinogen}

Fibrinogen concentration was measured using heat precipitation method. Two microhaematocrit tubes were filled with EDTA-anticoagulated blood. One was centrifuged and the total protein in the plasmas measured by refractometre. The second tube was heated at $56^{\circ} \mathrm{C}$ for 3 minutes, which precipitates the fibrinogen. The second tube was then centrifuged and the protein result read similarly. The protein result in the heated tube is substrate from the result in the unheated tube; the difference is equivalent to the fibrinogen that was removed from the plasma in the second tube by heating and centrifuging.

\section{Estimation of the Erythrocyte Sedimentation Rate (ESR)}

The ESR was estimated by Westergreen method [5,7]. The blood samples were transported in polystyrene bottles containing anticoagulant, and the ESR were determined within six hours of collection by the Westergreen method.

\section{RESULTS}

The mean values of serum total protein (TP), albumin, globulin and fibrinogen in the entire experimental subject are presented in table 1 .

The results showed that combined oral contraceptive with high estrogen content (group II) significantly reduced total protein and albumin and significantly elevated globulin and fibrinogen levels with respect to the control group $(\mathrm{p}<0.05)$. The combined oral contraceptive with low estrogen content on the other hand did not alter the value of these parameters significantly with respect to the control group. Comparison between groups II and III showed that while total protein and albumin levels in group administered combined oral contraceptive with high estrogen content were significantly higher than those administered combined oral contraceptive with low estrogen content $(\mathrm{p}<0.05)$, elevated globulin and fibrinogen levels were recorded that were statistically different from group III $(\mathrm{p}<0.05)$.

The mean values of the erythrocyte sedimentation rate (ESR) in groups I, II and III were: $4.05 \pm 0.05$, $6.00 \pm 0.09$, and $4.06 \pm 0.07 \mathrm{~mm} / \mathrm{hr}$, respectively. The combined oral contraceptive with high estrogen content (group II) significantly increased ESR with respect to the control (group I) and group III (combined oral contraceptive with low estrogen content) $(\mathrm{p}<0.05)$. The ESR value in group III however did not change significantly from the control group, figure 1. 
Sunday O. Ita et al.

Table 1. Estimation of the serum total protein, albumin, globulin and fibrinogen obtained from the control and oral contraceptive groups

\begin{tabular}{|lcccc|}
\hline Groups & Total protein $(\mathrm{g} / \mathrm{L})$ & Albumin $(\mathrm{g} / \mathrm{L})$ & Globulin $(\mathrm{g} / \mathrm{L})$ & Fibrinogen $(\mathrm{g} / \mathrm{L})$ \\
\hline I & $73.02 \pm 0.27$ & $49.74 \pm 1.70$ & $27.62 \pm 0.23$ & $28.68 \pm 0.18$ \\
II & $58.30 \pm 0.54^{\mathrm{a}}$ & $27.17 \pm 0.19^{\mathrm{a}} 33.51 \pm 0.70^{\mathrm{a}} 47.20 \pm 1.45^{\mathrm{a}}$ \\
III & $73.00 \pm 0.26^{\mathrm{b}}$ & $49.73 \pm 0.15^{\mathrm{b}} 27.62 \pm 0.23^{\mathrm{b}}$ & $27.60 \pm 0.18^{\mathrm{b}}$ \\
\hline
\end{tabular}

\section{Legend}

$\mathrm{a}=$ significantly different from group $\mathrm{I}(\mathrm{p}<0.05)$

$\mathrm{b}=$ significantly different from group II $(\mathrm{p}<0.05)$

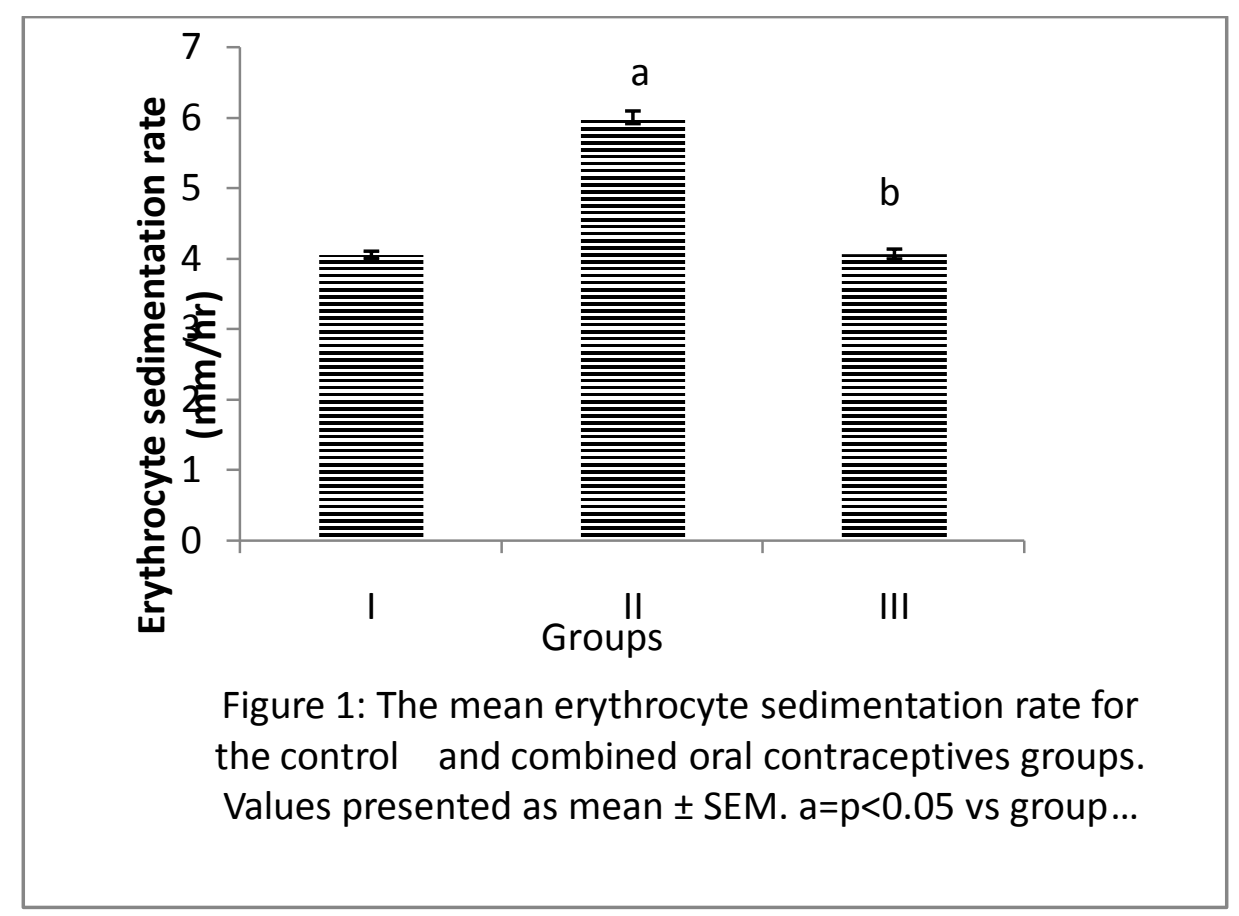

\section{DISCUSSION}

The influence of combined oral contraceptives on total protein, some plasma proteins, as well as the erythrocyte sedimentation rate (ESR) in apparently healthy women on oral contraceptives was investigated in this study. It was observed that combined oral contraceptive regimens with low estrogen content showed no significant alterations in serum total proteins and some of the investigated plasma proteins as well as the ESR when compared with none users (control) group. While the high estrogen content combined oral contraceptive markedly altered the aforementioned variables that were significantly different from the control group as well as group III (combined oral contraceptive with low estrogen content).

Interestingly, the mean value of the aforementioned variables in group III were however not significantly different from the control group (group I). While combined oral contraceptive with high estrogen content reduced total protein and albumin levels, it elevated the serum levels of globulin and fibrinogen, these findings agree with that of Obisesanet al., [8]. These workers reported that oral contraceptive induces significant increase in the serum levels of these parameters in women. It is an established fact that factor(s) that can reduce albumin level while at the same time increasing globulinand of course fibrinogen levels has/have the tendency to increase ESR as reported in this study.

The elevated fibrinogen could potent cardiovascular risk as fibrinogen is a precursor for fibrin, a principal player in coagulation process. A markedly elevation in fibrinogen concentration could instigates the aggregation of red blood cell, which might contribute positively to thrombotic process with adverse effect on cardiovascular disease [15]. Any substance administered through any route into the body with the tendency to increase and instigate activities of key players in coagulation process could pose a serious risk to inflammatory associated cardiovascular disorder, such as thromboembolic activities with tendency to developing hypertension. Fibrinogen level in women is normally higher 
than men [16,17], it is even higher in pregnancy as a result of markedly increase in estrogen and progesterone levels [18], which accounts for high ESR associated with pregnancy. In related studies on the haemorrheological effect of tri-phasic oral contraceptives, fibrinogen was reported to have increased either significantly or slightly [19, 20,21]; which has been corroborated in the present study. The combined oral contraceptive with high estrogen content presented a collaborative high fibrinogen levels and high ESR is reported in this study. Fibrinogen has been documented to be the plasma protein that contribute most to the aggregation of red blood cells and consequently increase ESR $[22,23]$.

The findings of this study appear to expose the possible inherent danger despite the advantage in preventing unwanted pregnancy, associated with administration of combined oral contraceptive with high estrogen content due basically to estrogen if taken without proper medical history and monitoring by experts. There could be more interesting revelations with regards to the capacity of high estrogen oral contraceptive on the body if other key players of inflammation are evaluated.

In summary the results of this study reveal firstly that combined oral contraceptive with high estrogen content induces a wider disparity gap in the distribution of albumin and globulin, as well as high level of fibrinogen. While the combined oral contraceptives appear to depress albumin synthesis it markedly elevated globulin. And secondly Combined oral contraceptive with high estrogen content increases rate of erythrocyte sedimentation necessitated by the aforementioned disparity perhaps with other contributing factors not investigated in this study.

\section{CONCLUSION}

It is therefore concluded that high estrogen content combined oral contraceptive by markedly altering serum total protein, albumin, globulin and fibrinogen distribution to increase erythrocyte sedimentation rate in apparently healthy women has the potential of increasing risk for associated inflammatory cardiovascular disorders in users if taken without caution. This is more important as chronic use of oral contraceptives containing estrogen may increase risk of raising blood pressure and the development of hypertension in users.

\section{REFERENCES}

[1] Hatcher, R. A., Trussel, J. and Stewart, F. 2000. Contraceptive Technology (18 $8^{\text {th }}$ ed). Ardent Media, New York. P.p. 23-30.

[2] Burke, A. E. 2011. The state of hormonal contraception today: Benefits and risks of hormonal contraceptives progestin-only contraceptives. Am J Obstet Gynecol., 205(4): $\quad$ 514-517.

[3] Shulman, L. P. 2011. The state of hormonal contraception today: benefits and risks hormonal contraceptives: combined estrogen and progestin contraceptives. American Journal of Obstetrics and Gynecology.205(4): 514-517.

[4] van Braeckel, D., Temmerman, M., Roelens, K. and Degomme, 2012.Slowing population growth for wellbeing and development.The Lancet.380 (9837): 84 - 85 .

[5] ICSH 1993. ICSH Recommendation for measurement of erythrocytes sedimentation rate. International Council for Standardization in Haematology.Journal of Clinical Pathology, 46(3): 198-203.

[6] Kakafika, A. I., Liberopoulos, E. N., Karogiannis, A. Athyros, V. G. and Mikhailidis, D. P. 2006. Dyslipidaemia, hypercoagulability and metabolic syndrome.CurrVascPharmacol., 4:175-183.

[7] Kanfer, E. J. and Nicol, B. A. 1997. Haemoglobin concentration and erythrocytes sedimentation rate in primary care patients. Journal of the Royal Society of Medicine, 90(1):16-18.

[8] Obisesan, K. A., Adenaik, F. A., Okunla, M. A. and Adenaika, A. A. 2002. Effects of oral contraceptives on total serum proteins, albumin, globulins and cholesterol levels in Ibadan, Nigeria.Journal of Obstetrics and Gynecology,21(3): 197- 199.

[9] Gaspard, U. J. 1990. Clinical aspects of the relationship between oral contraceptives, abnormalities in carbohydrate metabolism and the development of cardiovaxulen disease. American Journal of Obstetrics and Gynecology, 163:334 - 343.

[10] Gaspard, U. J. 1987. Metabolic effects of oral contraceptives. American Journal of Obstetrics and Gynecology, 157:1029 - 1021. 
[11] Daynes, R. A., Araneo, B. A., Hennebold, J. and Enidutunia, E. 1995. Steroids as regulators of the immune response.Journal of Investment and Dermatology, 105:148 - 198.

[12] Ahmed, S., Li, Q., Liu, L. and Tsui, A. O. 2012. Materials deaths averted by contraceptive use: An analysis of 172 countries. The Lancet, 380 (9837): 111-125.

[13] Henry, R. F. Cannon, D. C. and Winkleman, J. W. 1974. Clinical Chemistry, Principles and Techniques ( $2^{\text {nd }}$ ed). Haper and Row, Hagerstein, pp. $712-715$.

[14] Tietz, N. W. 1995. Clinical guide to laboratory tests ( $3^{\text {rd }}$ ed.). Saunders Company, Philadelphia. Pp. $105-106$.

[15] Lacombe, C., Bucherer, C., Ladjouzi, J. and Lelievre, J. C. (1988). Competitive role between fibrinogen and albumin on thixotropy of red cell suspensions.Biorheology, 25(1-2):349-354.

[16] Topol, E. J. 2002. Textbook of cardiovascular Medicine. Philadelphia, PA: Lippincott Williams \& Wilkins

[17] Fischbach, F. T. 2004. Manual of Laboratory and Diagnostic Tests. Philadelphia, PA: Lippincott Williams \& Wilkins

[18] Branch, D. W. 1992. Physiologic adaptations of pregnancy.Am J ReprodImmunol.,28:120-122

[19] Ernst, E., Schmolzl, C. Matsai, A. and Schramm, W. 1989. Haemorrheological effect of oral contraceptives.Contraception, 40(5):571-580

[20] Omsjo, I. H., Oian, P., Maltau, J. M. and Osternd, B. 1989. Effects of two triphasic oral contraceptives containing ethiniloestradiol plus levonergestrolgestogene on blood coagulation and fibrinolysis.ActaObstetGynecol Scand., 68:27-30

[21] Nolelovitz, M., Kitchens, K. S. and Khan, P. Y. 1992. Chnages in coagulation and anticoagulation in women taking low dose triphasic oral contraceptives: a controlled comparative 12 month clinical trial. Am J ObstetGynecol167:1255-61

[22] Bedell, S. E and Bush, B. T. (1985). Erythrocytes sedimentation rate from folklore to facts.Am J Med., 78:1001-1009.

[23] Sox, H. C. and Liang, M. H. (1986). The erythrocyte sedimentation rate.Ann Int Med., 104:515-523. 